\title{
DIGITAL TRANSFORMATION INITIATIVES IN INDIAN HIGHER EDUCATION: A CRITICAL ANALYSIS FROM PEDAGOGIC PERSPECTIVES
}

\begin{abstract}
COVID-19 pandemic has impacted all aspects of human life including higher education. With the advent of digitalization of educational contents and its surging acceptability in the society of today, there is a tremendous scope to expand education to every nook and corner of the country. The Government of India has taken decisive digital initiatives to carry out large-scale digital reforms in higher education. While technology-enabled initiatives or platforms in line with Massive Open Online Courses such as Swayam have seen the use of technologies and Diksha, a platform that aids teachers with digital and tech-based teaching solutions, the Government is also emphasizing on boosting the use of tools such as virtual lab, a virtual reality enabled classrooms or curated online content for both students and teachers. This paper sincerely depicts and analyses the detailed descriptions of all the major initiatives taken by the Government of India in the field of higher education in a critical perspective keeping in mind the pertinent digital questions in terms of its divide, access, equity, and pedagogy. It also depicts some measures to be taken, purely from the digital pedagogic perspective as pedagogy has not yet become the core of higher education affairs in India, to materialize the knowledge construction virtually or digitally in higher education institutions.
\end{abstract}

Keywords: Digital-pedagogy; digital-platforms; digital-divide; Arpit; Swayam; Badal; GIAN. DOI: 10.51180/RPS.2020.15.2.004.

\section{Author}

\section{Arbind Kumar Jha}

Dean School of Education, Ambedkar University, Ph.D, Professor

(Lucknow, India)

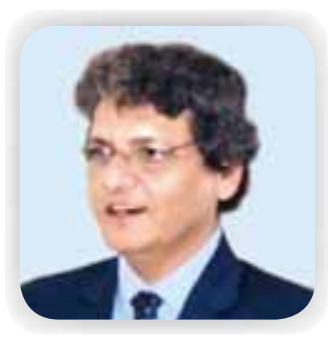

\section{Introduction}

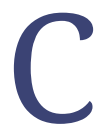
OVID-19 pandemic has impacted all aspects of human life including education in general and higher education in particular. But, the good thing is that with the advent of information and communication technology and its increasing acceptability in the society of today, there is a tremendous scope to expand education to every nook and corner of the country, for enhancing awareness and improving understanding. India as a nation is on a growth path in the higher education sphere and digitization is supporting the collective efforts of public and private sectors to realize the dream of becoming the education hub of the world.

India's higher education is evident with the increasing use of ICT, Cloud Computing, Artificial Intelligence, and Virtual Reality in day-to-day practices. The Government of India has committed itself by prioritizing advanced uses of ICT to bring phenomenal changes such as Revitalising Infrastructure and Systems in Education (RISE) scheme. While technology-enabled initiatives or platforms in line with Massive Open Online Courses (MOOC) such as Swayam (for teachers' education) have 
seen the use of technologies, the Government is also emphasizing on boosting the use of tools such as virtual lab, virtual reality (VR)-enabled classrooms or curated online content for both students and teachers. Swayam, an online life-long training platform developed with the help of Microsoft, or Diksha, a platform that helps teachers with digital and techbased teaching solutions, is paramount strives in revamping the digital education platforms.

India is going to be one of the youngest nations in the world and with over 140 million people in the college-going age group by 2030 , one in every four graduates in the world will be a product of the Indian higher education system. Keeping this in perspective, India has taken some concrete and much-awaited transformational initiatives to truly transform higher education in recent times such as SWAYAM; SWAYAM Prabha; NDL (National Digital Library); National Academic Depository; 5e - Shodh Sindhu; Virtual Labs; e-Yantra; Campus Connectivity; Talk to a Teacher; Ask a Question; e-Acharya; E-Kalpa; FUSSEE (The Free and Open Source Software for Education); e-Vidwan; Spoken Tutorial; Central Cloud Infrastructure; NAD (National Academic Depository); BADAL; OSCAR; Virtual Learning Environment; Text Transcription of Video Content; e-PG Pathshala; etc. Approximately thirty such Digital Initiatives have been taken by the Government of India in Higher Education.

\section{A brief description of Digital Initiatives in the form of digital platforms Indian Higher Education is as under:}

ARIIA: ARIIA (Atal Ranking of Institutions on Innovation Achievement) is an initiative of MHRD to rank all major universities and HEls in India on indicators related to 'Innovation and Entrepreneurship Development' amongst students and faculties.

ARPIT: The Ministry of Human Resource Development has officially launched Online Annual Refresher Programme in Teaching (ARPIT) in 2018, a major and unique initiative of online professional development of fifteen lakh higher education faculty using the MOOCs platform SWAYAM. For implementing ARPIT, discipline-specific National Resource Centres (NRCs) have been identified to prepare online training material with a focus on the latest developments in the discipline for transacting revised curriculum based on pedagogical improvements and methodologies.

Ask a Question: Ask A Question is a unique platform through which students from science and engineering institutions can ask questions and dedicated faculty from IIT Bombay answers them. Questions can be asked either online or during an interactive sessions which are live.

BAADAL: It is an MHRD initiative developed as an NME-ICT cloud for academic purposes. It is a cloud orchestration and virtualization management software initiated by MHRD under the NMECT scheme and developed and maintained by IIT Delhi. It ensures optimal utilization of the infrastructure and speeds up the development and deployment of e-Government applications for academic needs.

Campus Connectivity: Establishment of one GBPS Connectivity to universities and twenty 512 Kbps broadband connectivity to colleges has been provisioned under NMEICT. Six hundred universities have been already connected through one GBPs Optical Fibre and above twenty thousand colleges have already been connected with ten Mbps bandwidth.

Diksha: Diksha has more than 80,000 eBooks for classes I to XII created by CBSE, NCERT, and States/UT which are available in multiple languages.

e-Acharya: e-Acharya is an integrated e-content portal. It hosts all e-content projects, developed/funded under the NME-ICT. There are more than seventy projects on e-content under NME-ICT which are developed/being developed in various subject disciplines (sciences, social sciences, arts, engineering, etc.) through 
various Indian colleges, universities, and institutes.

e-Adhayayan: e-Adhyayan is a platform to provide $700+$ e-Books for the PostGraduate Courses. All the e-Books are taken from the courses of e-PG Pathshala. It also has facilities for video content.

e-PG PATHSHALA: e-PG Pathshala is an initiative of the MHRD under its NME-ICT (National Mission on Education through ICT) being executed by the UGC. The content and its quality is the key component of the education system, high quality, curriculum-based, interactive e-content in seventy subjects across all disciplines of social sciences, linguistics, and languages have been developed by the subject experts working in Indian Universities.

e-Acharya: e-Acharya is an integrated e-content portal. It hosts all e-content projects, developed/funded under the NME-ICT. There are more than seventy projects on e-content under NME-ICT which are developed/being developed in various subject disciplines (sciences, social sciences, arts, engineering, etc.) through various Indian colleges, universities, and institutes.

e-Kalpa: e-Kalpa is an MHRD/NMCEICT initiative creating Digital Learning Environment for Design in India has successfully demonstrated the achievement of:

Digital online content for learning design with e-learning programme on design

Digital Design Resources Database including the craft sector

Social networking for higher learning with collaborative learning space for design

Design inputs for products of NME-ICT

It has already more than one hundred sixty courses on Design Learning in different domains.

e-SodhSindhu: More than 15,000 international electronic journals and ebooks are made available to all the higher educational institutions through the eShodhSindhu initiative. This allows access to be the best educational resources in the world using digital mode. The INFLIBNET,
Gandhinagar, Gujarat is implementing the Scheme.

e-Vidwan: The 'Information and Library Network' (INFLIBNET) Centre took the initiative called "Vidwan: Expert Database and National Researcher's Network" with the financial support from NMEICT. The objectives of VIDWAN is to i) collect academic and research profiles of scientists, faculty and research scientists working in leading academic and R\&D organizations in India and abroad; ii) quickly and conveniently provide information about experts to peers, prospective collaborators, funding agencies, policymakers and research scholars in the country; iii) establish communication directly with the experts who possess the expertise needed by research scholars; iv) identify peer reviewers for review of articles and research proposals; v) create information exchanges and networking opportunities among scientist.

e-YANTRA: e-Yantra platform has been started to introduce Robotics into engineering education so that students may be engaged in hands-on application of principles of engineering computer science and mathematics. Presently, e-Yantra has been implemented in 100 colleges. e-Yantra is creating skills by setting up lab infrastructure for project-based learning and training teachers in these 100 engineering colleges.

FOSSEE: FOSSEE project sanctioned to IIT Bombay has been promoting the use of open-source software in educational institutions (http://Fossee.in). It does through instructional material, such as spoken tutorials, documentation, such as textbook companions, awareness programs, such as conferences, training workshops, and Internships.

GIAN: GIAN (Global Initiative of Academic Networks) is a Government approved programme aiming to tap the talent pool of scientists and entrepreneurs internationally to encourage their engagement with the institutes of higher education in India to augment the country's existing academic resources accelerate 
the pace of quality reform, and elevate India's scientific and technological capacity to global excellence.

IMPRINT: IMPRINT (Impacting Research Innovation and Technology) is the first of its kind MHRD supported PanIIT+IISc joint initiative to address the major science and engineering challenges that India must address and champion to enable, empower and embolden the nation for inclusive growth and self-reliance. This novel initiative with a two-fold mandate is aimed at developing new engineering education policy and creating a road map to pursue engineering challenges

IMPRINT provides the overarching vision that guides research into areas that are predominantly socially relevant.

NAD: The vision of NAD (National Academic Depository) is born out of an initiative to provide an online storehouse of all academic awards. NAD is a twenty-four by seven online storehouse of all academic awards viz. certificates, diplomas, degrees, mark-sheets, etc. dully digitalized and lodged by academic institutions/ boards/eligibility assessment bodies.

National Digital Library of India (NDLI): NDLI is an all-digital library that stores information (metadata) about different types of digital contents including books, articles, videos, audios, thesis, and other educational materials relevant for users from varying educational levels and capabilities. It provides a single-window search facility to access digital contents currently existing in India as well as other digital sources under a single umbrella.

NIRF: NIRF (National Institutional Ranking Framework) outlines a methodology to rank institutions across the country. The methodology of ranking is based on the parameters such as - (i) Teaching Learning and Resources, (ii) Research and Professional Practices, (iii) Graduation Outcomes, (iv) Outreach and Inclusivity, and (v) Perception.

NISHTHA: NISHTHA -An integrated Teacher Training Portal and Mobile App

OSCAR: OSCAR (Open Source Courseware Animations Repository) provides a repository of web-based interactive animations and simulations, that we refer to as learning objects (LOs). These learning objects span topics in science and engineering at the college level and mathematics and science at the school level. Students and teachers can view, run, and download these learning objects.

NROER: NROER (National Repository of Open Educational Resources). With approximately 16000 registered users and 14527 e-learning resources, NROER is one of an excellent initiative launched by the Ministry of HRD. Students visiting the NROR platform gets exposure to elibraries, e-books, e-courses, chance to participate in events online, and themebased education. Apart from this, students can access the website in both Hindi and English languages.

SHAKSHAT: This portal has been initiated to facilitate the concept of lifelong learning for those who are in employment, students, and teachers to get knowledge free of cost.

The content has been developed by IGNOU, University of Delhi, KVS (Kendriya Vidyalaya Sangathan), NVS (Navodaya Vidyalaya Sangathan), NIOS (National Institute of Open Schooling) and NCERT (National Council for Educational Research and Training).

ShodhGanga: It is a digital depository platform for the Indian Electronic Theses and Dissertations. It facilitates open access to Indian theses and dissertations to the academic community worldwide.

ShodhGangotri: At this e-platform, all the research scholars/research supervisors in universities are requested to deposit their electronic version of approved synopsis submitted by research scholars to the universities for registering themselves for the Ph.D. programme.

Spoken Tutorial: This project helps everyone learn various Free/Libre and Open Source Software all by oneself. It is a self-paced multilingual course which ensures that anybody with a computer and a desire for learning can learn from any place, at any time, and in a language of 
their choice. The Internet is not required to use Spoken Tutorials.

SWAYAM: SWAYAM (Study Webs of Active Learning for Young Aspiring Minds) is an interactive learning platform that has been developed by MHRD (Ministry of Human Resource Development) and NPTEL (National Programme on Technology Enhanced Learning), IIT (Indian Institute of Technology) Madras with the help of Google INC and Persistent Systems Ltd. SWAYAM seeks to bridge the digital divide for students who have hitherto remained untouched by the digital revolution and have not been able to join the mainstream of the knowledge economy" (swayam.go.in). It is capable of hosting around two thousand courses and eight hundred hours of learning encompassing School Education; Undergraduate and Post-graduate courses. It has also contents of professional courses like law and engineering. All the courses delivered through SWAYAM are available free of cost. However, those wanting and desiring for certifications will have to pay a nominal fee and complete the course successfully.

SWAYAM PRABHA: The Swayam Prabha is a group of thirty-two DTH (Direct to Home) channels devoted to the teaching of high-quality educational programmes on twenty-four by seven basis using the GSAT-15 satellite. Every day, there will be new content and repeat telecasts. The contents аге provided by UGC; CEC; IIT; NPTEL; IGNOU; NCERT and NIOS.

Talk to a Teacher: This has been developed by IIT Bombay to provide free access to a few selected graduate and postgraduate courses, taught at IIT Bombay by distinguished faculty members and scholars.

Virtual Labs: This has been started to provide remote-access to Labs in various disciplines of Engineering and Sciences. These Virtual Labs help all students at the levels of undergraduate and postgraduate. Research scholars also get benefitted from these. Based on the complete Learning Management System, at these Virtual Labs, students can avail of the vari- ous tools for learning, including additional web-resources, video-lectures, animated demonstrations, and self-evaluation. Here, costly equipment and resources are shared.

A Critical Analysis from Pedagogic Perspective: The steady onset of the Digital India vision is having a profound effect on our lives. Digital technology which is also known as disruptive technologies has helped to fast pace the digitalization and consequently a new kind of transparency, efficiency, and accountability are found in the field of higher education. At the same time digitalization has brought about disruptive changes with the tremendous potential to have radically altered the conventional landscape of paradigm of higher education teaching and learning. As far as the pedagogic perspective is concerned, there is a lot more to be needed. There are huge challenges in the digitalization of higher education as digital resources and internet connectivity are not the major problems on the one hand and the other, there is a shortage of digital literate and pedagogic oriented teachers in the field of higher education. Due to digital technology as a catalyst, education is advancing from a knowledge-transfer/delivery model to an active, self- directed, collaborative, and above all engaging model.

\section{Digital Pedagogic Perspective:}

As per perceived perception, "digital pedagogy is considered as the use of electronic elements to enhance or to change to the experience of education" (Brian Croxall, 2013). It has also been termed as an attempt to use technology to change teaching and learning in numerous ways. Importantly, some argue that merely using electronic elements in our teaching does not guarantee that we are practicing digital pedagogy. Digital pedagogy incorporates several axiomatic changes to conventional pedagogy and shares its frameworks with constructivist and constructionist approaches, in which students construct their knowledge in sociocultural 
settings. Here comes a role of epistemic (theory of knowledge) dimension of pedagogy in general and digital pedagogy in particular. It has been asserted time and again that it is an epistemology that provides guided lives to pedagogy (Jha, A. K. 2005). Consequently, it can be said that it is the pedagogy that must provide guided direction to online teaching and learning. Being co-construction of knowledge as the central to digital pedagogy, it transcends and encompasses learning along with teaching. A digital pedagogy includes planning for learning which is less content than problem-solving based.

Digital pedagogy demands not only to know how to use of contemporary digital technologies in teaching and learning but also to be acquainted and versed well with modern paradigms of pedagogy and pedagogic approaches. Fundamentally, it is assumed that digital pedagogy has roots in the theory of constructivism and constructionism. Therefore, the econtents that we provide to the teachers to be used for teaching and learning purposes through different e-platforms, it must adhere to the constructivist and constructionist teaching and learning design used for online teaching digitally. It is also presumed that digital pedagogy is not about using digital technologies for teaching rather it is about approaching those tools from a critical pedagogic perspective in the domain of constructivist and constructionism.

Among many important factors, Digital Pedagogy demands to focus on collaboration, inclusion, and class participation. Design for inclusion demands ensuring that the technology being incorporated allows everyone to participate and therefore, a teacher has to be mindful of the digital divide and that not all of the students have access and are tech-savvy. For class participation, two things are required like knowledge about engaging tools that work the best and understanding of digital pedagogic approaches. The selection of a particular pedagogic approach depends on the epistemic dimension and its understanding of a particular pedagogic approach and its digital strategies. There is a selective range of pedagogical theories that apply to Digital Pedagogy in particular and which are frequently used are - Constructivism; Constructionism; Active Learning; Problem Based or InquiryBased Learning; Andragogy, etc.

There are Digital Pedagogues who prefer not to use a single pedagogic model but the blends of the pedagogic model of Innovative and Creative Pedagogy, Constructivist and Critical Pedagogy, and Constructionist Pedagogy. Innovation has been defined by various thinkers differently. Some viewed it as the creation of better or more effective products, others have viewed it as processes and ideas that are useful for solving the problems of education. Creative digital pedagogy helps online learners how to learn constructively and creatively and become creators and constructors of themselves. Lately, pedagogues have emphasized the concept of 'construction is creativity'. Epistemic construction of knowledge is epistemic creativity.

In the light of the above discussion, it can be underlined that though there are so many transformational digital initiatives in the form of e-contents and different eplatforms on the part of Government of India in the field of higher education but, there is hardly any which is based on sound digital pedagogic perspective.

Digital Divide in India: Due to the Covid-19 pandemic and lockdown, there is a huge jump in digitalization profoundly evident in Indian higher education. Digitalization is putting its thumping stamp and its unflinching authority in higher education incessantly. But, the question of the digital divide and digital equity and access have become more critical today in the field of higher education in India.

As described by Wikipedia, "the term digital divide refers to the gap between people with effective access to digital and information technology and those with very limited or no access at all. It includes the imbalances in physical access 
to technology as well as the imbalances in resources and skills needed to effectively participate as a digital citizen. The digital divide is an alarming reality in India and heavy cost to access new technology will set the stage for the digital divide i.e. digital discrimination gravely". Digital itliteracy is on a constant rise in India.

In urban India, things like smartphones, laptops, and other electronic gadgets are considered as common articles and available to all. There is a vast majority who lack these and don't have unhindered access to the internet. According to the Telecom Statistics India (2019), "telephone subscribers in rural and urban India stands at 514.27 and 669.14 million respectively. This means that a widening disparity exists between rural and urban telephone subscribers, which stops the sizeable rural population from existing in the online/digital world".

As far as Internet penetration is concerned in India, according to IAMAI (2019), among the $12+$ age group, there is $40 \%$ penetration at All India level, $54 \%$ in the Urban Area and just $32 \%$ at the level of Rural India. This data itself speaks volumes of the digital divide in India in terms of access and equity. At the same time, it can't be denied that there has been an increase in penetration of Internet users up to $65 \%$ in the top eight metros. Rural penetration is also growing at a faster rate at $18 \%$. As far as distribution of internet users by gender in percentage is concerned, at all India level users, the ratio of male and female is $65 \%$ to $35 \%$, at the urban level users, it is $60 \%$ to $40 \%$ and at the rural level users, it is $69 \%$ to $31 \%$.

In its 75th round of surveys, the NSSO's on Social Consumption in Education for the year 2017-18 has underlined that $76 \%$ of households that have at least one student as a member belong to rural India. A close analysis of this fact reflects that rural India has disproportionately very low and scarce access to both -- internet uses and the availability of computers. If one compares with urban households, it is beyond doubt that rural students have three times lower access to the internet. Also, if we take a quick look at the all-India figures, only $28 \%$ of households with a currently enrolled student have any internet access. It means, during the Covid-19 pandemic, as has been claimed that 70 to $80 \%$ of students took online classes, on the contrary approximately 70 to $80 \%$ of current rural students had no internet access at all.

Ookla's Speedtest Global Index (March 2020) has ranked India at 130 th in terms of mobile use and 71st in terms of fixed-line internet speeds. Therefore, considering access, Governmental measures must address issues of bandwidth inequities. India has 625.42 million "broadband" internet subscriptions. In other words, half of Indians don't have access to broadband. Therefore, the Government of India will have to approach access through the lens of modern website/application design, and domestic network capacity.

\section{Conclusion}

In terms of policy and planning, MHRD (Ministry of Human Resource Development) which is now renamed as Ministry of Education (NPE, 2020), Government of India is largely responsible for the development of the educational infrastructure in general and digital infrastructure in particular of Higher Education Sector in India. Under a planned development process, the Ministry of Education in recent times has taken the concrete measures to expand the access and qualitative improvement in Higher education through various Transformational Digital Initiatives in terms of e-contents and e-platforms commendably. Despite these phenomenal initiatives, still, the e-contents that are there in various form is not even closer to digital pedagogy as all most all are divorced from the epistemic dimension of digital pedagogic discourses. The academicians engaged in the field of higher education will have to acquaint themselves with the pedagogic orientation as pedagogy in a general and epistemic dimension of 
pedagogy, in particular, has not occupied a center stage in the art and science of teaching and learning. Conclusively it can be stated that the entire higher education teaching-learning paradigm is far from the digital-epistemic-pedagogical perspective as pedagogy in general and digital pedagogy, in particular, has not yet become the core of higher education affairs in India institutionally, to materialize the knowledge construction virtually or digitally in higher education institutions. The digital divide in terms of access and equity is still a major challenge in India which needs immediate and stark attention on behalf of the Government of India to have comprehensive strategies to make a decisive intervention immediately to address the accelerating need for everyone to be digitally connected equitably.

\section{References}

1. Jha, A. K. (2009). Constructivist Epistemology and Pedagogy: Insight into Teaching Learning and Knowing. New Delhi: Atlantic Publisher and Distributors

2. Jha, A. K. (2005). Nyaya Philosophy: Epistemology and Education. New Delhi Standard Publisher (India)

3. Kenneth, Deepak, 2002, 2004. - URL: http://www.mit.edu/people/kken/PAPERS

4. National Education Policy 2020. - URL: https://static.pib.gov.in/WriteReadData/userfiles/ NEP_Final_English_0.pdf

5. Key Indicators of Household Social Consumption on Education in India. — URL: http://www. mospi.gov.in/sites/default/files/NSS75252E/KI_Education_75th_Final.pdf

6. Digital Pedagogy? - URL: https://www.briancroxall.net/digitalpedagogy/what-is-digitalpedagogy/

7. Decoding Digital Pedagogy: Beyond the LMS. — URL: https://guides.library.utoronto.ca/c. php?g=448614\&p=3340274

8. Digital divide. — URL: https://en.wikipedia.org/wiki/Digital_divide

9. DIGITAL IN INDIA. 2019. - ROUND 2 REPORT. - URL: https://cms.iamai.in/Content/ ResearchPapers/2286f4d7-424f-4bde-be88-6415fe5021d5.pdf

10. Atal Ranking of Institutions on Innovation Achievement — URL: https:/ariia.gov.in/

11. Annual Refresher Programme in Teaching (ARPIT) —URL: https://arpit.nta.nic.in/cms/public/ home.aspx

12. BAADAL — URL: https://baadal.nmeict.in/

13. Diksha - URL: https://www.india.gov.in/spotlight/diksha-national-digital-infrastructureteachers

14. e-Adhayayan — URL: http://e-adhyayan.org/

15. e-PG PATHSHALA - URL: https://epgp.inflibnet.ac.in/Home

16. e-Acharya - URL: http://eacharya.inflibnet.ac.in/vidya-mitra/

17. e-Kalpa - URL: http://workshop.nkn.in/2014/images/presentation/2015/eKalpa.pdf

18. e-SodhSindhu - URL: https://ess.inflibnet.ac.in/

19. e-YANTRA — URL: https://portal.e-yantra.org/; https://e-yantra.org/

20. FOSSEE - URL: http://Fossee.in

21. GIAN - https://gian.iitkgp.ac.in

22. IMPRINT - URL: http://imprint-2.in/Imprint-II/HomePage

23. National Academic Depository (NAD) - URL: https://nad.gov.in/

24. National Digital Library of India (NDLI) - URL: https://www.ndl.gov.in/

25. National Institutional Ranking Framework (NIRF) - URL: https://www.nirfindia.org/

26. NISHTHA — URL: https://itpd.ncert.gov.in/

27. Open Source Courseware Animations Repository (OSCAR) — URL: http://oscar.iitb.ac.in/

28. National Repository of Open Educational Resources (NROER). — URL: https://nroer.gov.in/ welcome

29. SHAKSHAT. - URL: https://sakshat.ac.in/

30. ShodhGanga. — URL: https://shodhganga.inflibnet.ac.in/

31. ShodhGangotri. — URL: https://shodhgangotri.inflibnet.ac.in/

32. Spoken Tutorial. — URL: https://spoken-tutorial.org/ 
33. Study Webs of Active Learning for Young Aspiring Minds (SWAYAM). — URL: https://swayam. gov.in/

34. SWAYAM PRABHA. — URL: https://www.swayamprabha.gov.in/

35. Talk to a Teacher. — URL: https://co-learn.in/

36. Virtual Labs. - URL: https://www.vlab.co.in/ 